\title{
METHOD OF AUTOMATIC CORRECTION OF NEUTRON MONITOR DATA FOR PRECIPITATION IN THE FORM OF SNOW IN REAL TIME
}

\author{
V.L. Yanchukovsky \\ A.A. Trofimuk Institute of Oil and Gas Geology \\ and Geophysics $S B R A S$, \\ Novosibirsk, Russia,YanchukovskiyVL@ipgg.sbras.ru
}

\author{
V.S. Kuz'menko \\ A.A. Trofimuk Institute of Oil and Gas Geology \\ and Geophysics $S B R A S$, \\ Novosibirsk,Russia,KuzmenkoVS@ipgg.sbras.ru
}

\begin{abstract}
We have carried out an experimental study of the influence of precipitation in the form of snow on measurements of the neutron flux intensity near Earth's surface. We have examined the state of the snow cover and its density, and found out that the density depends on the depth of the snow cover. Using the experimental results, we estimate the neutron absorption path in the snow. Changes in snow cover by $10-12 \mathrm{~cm}$ at a depth of $80 \mathrm{~cm}$ are shown to cause variations in the monitor count rate with an amplitude of $0.9 \%$. At the snow depth of $80 \mathrm{~cm}$, the neutron monitor count rate decreases by about $8 \%$. The observed variations should be attributed to the meteorological effects of cosmic rays. The absorption coefficient of neutrons in the snow was also found from the
\end{abstract}

correlation between the count rate of the neutron monitor and the amount of snow above the detector. We propose a real-time correction of the neutron monitor data for precipitation in the form of snow. For this purpose, we implement continuous monitoring of the amount of snow cover. The monitoring is provided by a snow meter made using a laser rangefinder module. We discuss the results obtained.

Keywords: cosmic rays, neutron monitor, meteorological effects, absorption range.

\section{INTRODUCTION}

For continuous observations of the intensity of the cosmic ray (CR) nuclear-active component in the atmosphere, the NM-64 neutron monitor is used as a standard instrument of the World network of CR stations [Dorman, 1975]. In Novosibirsk, the neutron monitor consists of four sections with a total particle collection area of $24 \mathrm{~m}^{2}$, thus allowing for $0.1 \%$ statistical accuracy of hourly data. Sensitivity of the neutron monitor in the range of primary cosmic ray energies is generally from units of $\mathrm{GeV}$ to $30 \mathrm{GeV}$ with a maximum for particles with energy of $5.6 \mathrm{GeV}$ [Yanchukovsky, Filimonov, 1995]. The CR flux in this energy range is subject to the greatest modulation due to processes on the Sun and in the interplanetary space (in the heliosphere), Earth's magnetosphere and atmosphere. However, the neutron flux intensity variations observed may also include variations caused by changes in the thickness of the absorber above a detector, which represent precipitation in the form of snow. Snow over a neutron monitor can lead to two opposite effects. The main one is the absorption effect, which causes the count rate of the neutron monitor to decrease; yet the effect of neutron generation in snow [Dorman, 1972], leading, on the contrary, to an increase in the monitor counting rate, may also be observed. The neutron flux intensity variations caused by precipitation in the form of snow may amount to several percent. These variations should be correctly accounted for in initial data from the neutron monitor.

\section{NEUTRON FLUX INTENSITY VARIATIONS CAUSED BY PRECIPITATION IN THE FORM OF SNOW}

In recent years, many papers have been published on the relationship between CR neutron fluxes and the amount of precipitation in the form of snow [Heye et al., 2020; Sigouin, Si, 2016; Rivera Villarreyes et al., 2011; Schattan et al., 2017]. The papers listed and the reviews they contain address topical applied problems - to estimate the snow water equivalent (SWE) and soil moisture from CRs. SWE is measured to model and predict floods, as well as in the interests of agriculture. Sigouin and Si [2016] have explored the possibility of using the slow CR neutron flux to estimate SWE. The method proposed by Sigouin and $\mathrm{Si}$ allows remote measurements over large areas (within a radius up to $300 \mathrm{~m}$ ). A probe was calibrated for two winters, using traditional SWE measurement methods. The method can also assess deposits of soil moisture. It has recently been shown [Heye et al., 2020] that the use of Cosmic Ray Neutron Probes (CRNP) to measure the amount of snow is a promising method of monitoring the evolution of snow cover (SC). CRNP require less maintenance than conventional sensors. Heye et al. [2020] have adopted thermal and epithermal neutron detectors in the probes. Testing various methods for converting the neutron count rate into SC characteristics has shown that all methods can fairly well determine the amount of snow during precipitation. One of the new measurement methods [Rivera Villarreyes et al., 2011] 
able to estimate the integral soil moisture is groundbased sounding by CR neutrons, more precisely, by Earth albedo neutrons. Rivera Villarreyes et al. [2011] measured Earth albedo neutrons in an agricultural field in northern Germany. For checking purposes, the neutron albedo measurement was accompanied by other measurements of soil moisture. Overall, the study describes a procedure of sounding by Earth albedo neutrons with devices that are now commercially available. Schattan et al. [2017] have estimated characteristics of a ground-based CR neutron detector for monitoring SC in the Austrian Alps. Estimated neutrons were compared with continuous SWE and SC depth measurements at an automatic meteorological station. In addition, several spatially distributed SC and SWE maps obtained from groundbased laser scanning were used. A strong nonlinear correlation was found for both SC and SWE. The average coverage area of the ground-based detector ranges from 230 to $270 \mathrm{~m}$.

The snow effect on the intensity of the neutron flux detected was studied with the detectors shown in Figure 1.

Neutrons are detected with the aid of gas-discharge counters SNM-15 [Asatiani et al., 1969], as in the NM64 neutron monitor, according to the reaction

$$
\mathrm{B}_{5}^{10}+n_{0}^{1} \rightarrow \mathrm{Li}_{3}^{7}+\mathrm{He}_{2}^{4} \text {. }
$$

The counter efficiency is maximum for thermal neutrons and is over $40 \%$ [Asatiani et al., 1969]. The SNM-15 counters are grouped in units of three, as shown in Figure 1, $a$. To explore the possible thermal neutron flux anisotropy, two detector units were located one above the other with a $1 \mathrm{~mm}$ thick cadmium sheet between them. Each side of these detector units is also covered with sheet cadmium (Figure 1,c). Continuous detection of neutrons with these detectors started on August 19, 2013 in a one-story building of the CR station Novosibirsk. Daily average counting rates of upper $N_{1}$ and lower $N_{2}$ detector units for the annual period from January 2014 to January 2015 were used. During this period, regular measurements of snow depth on the roof of the building were also carried out. From continuous observations made during this period, ratios between detector count rates $R$ and the anisotropy $A$ were found:

$$
\begin{aligned}
& R=N_{1} / N_{2}, \\
& A=\frac{N_{1}-N_{2}}{N_{1}+N_{2}} .
\end{aligned}
$$

The results (Figure 2) show that the seasonal variation in the thermal neutron flux anisotropy is mainly due to the presence of precipitation in the form of snow.

In connection with significant variations in the intensity of the neutron flux caused by atmospheric precipitation in the form of snow, it becomes necessary to regularly monitor SC depth above the detector in real time. The $\mathrm{CR}$ stations located at high and middle latitudes, as well as in mountains at low latitudes, are affected by snow, which accumulates above detectors and distorts the neutron flux variations observed. Hence, the neutron monitor $\mathrm{CR}$ observations require an appropriate correction. Kobelev et al. [2020] have adopted the so-called reference station method. The principle of the method consists in comparing isotropic variations at the test and reference stations. It is supposed that there is no snow at the reference station. In this case, the difference between neutron flux variations is taken to stem from the influence of only $\mathrm{SC}$ on the count rate of a detector in hand.

Correctly accounting for SC above a neutron monitor in real time requires continuous data on the specific gravity of snow above the detector, with known SC depth and density.

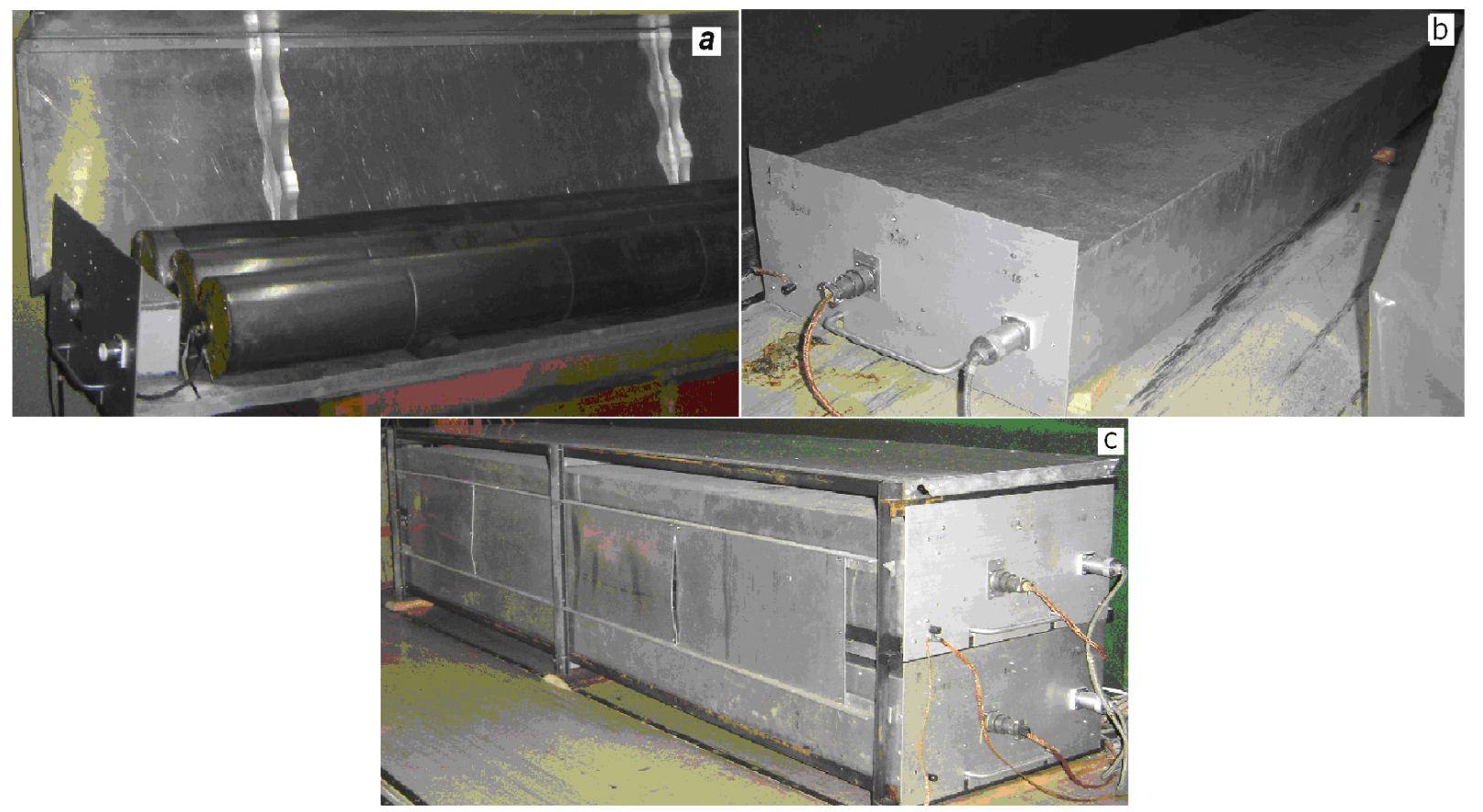

Figure 1. Neutron detector: arrangement of counters in a unit $(a)$; a single remote detector unit $(b)$; paired detector units $(c)$ 


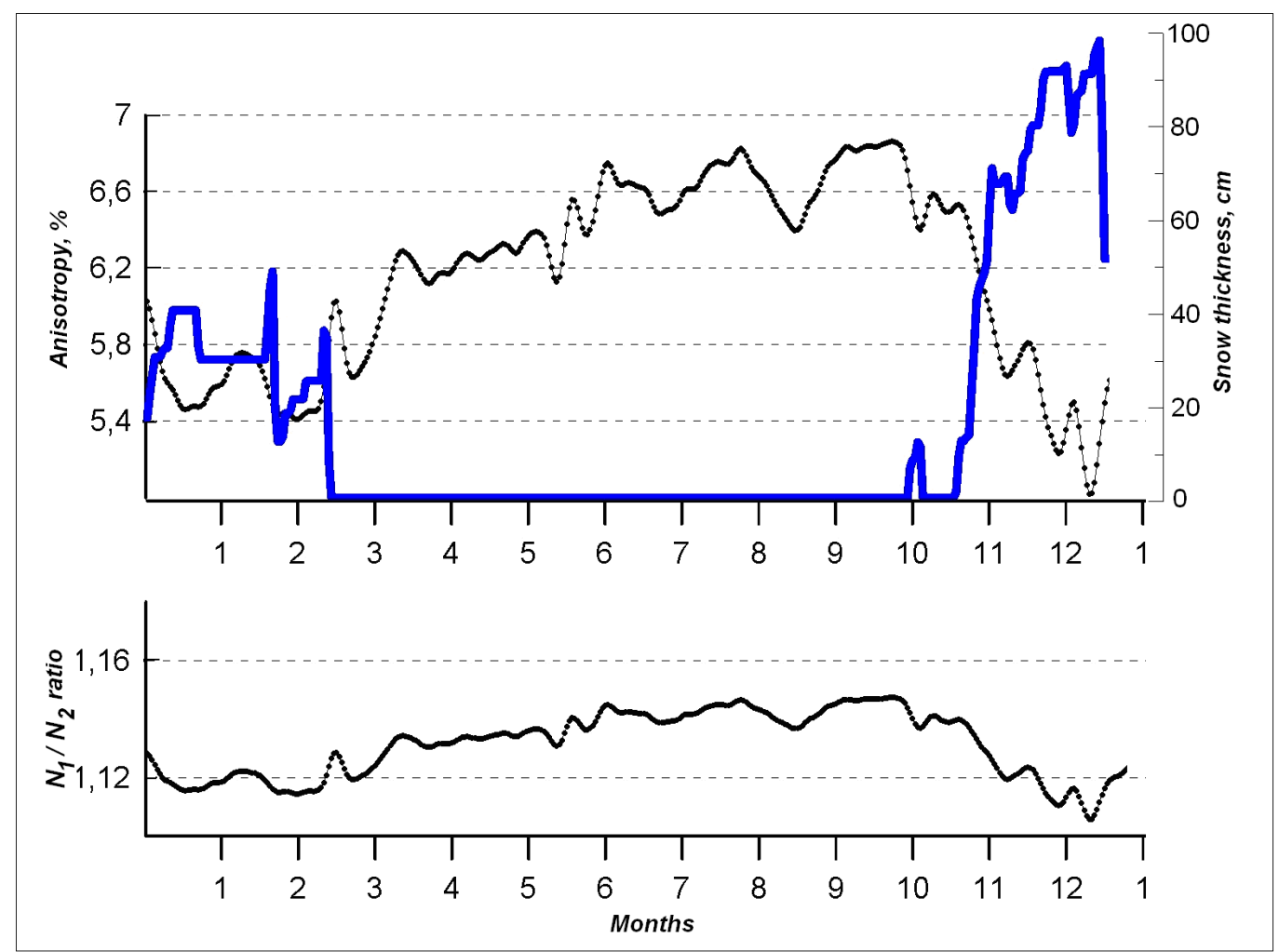

Figure 2. Seasonal variations in the thermal neutron flux near Earth's surface: at the top — flux anisotropy (black curve) and snow depth (blue curve); at the bottom — a ratio between count rates of detectors $N_{1}$ and $N_{2}$

\section{STATE OF SNOW COVER AND ITS DENSITY}

The snow density varies significantly depending on its state (dry, wet), shape of snowflakes (flakes, medium snowflakes, grains), conditions under which it fell (in calm or windy weather), lying time (fresh, settled, virgin), etc. Some averaged snow density values obtained from longterm observations

[https://tehtab.ru/Guide/GuideMedias/GuideWater/SnowD ensityAndHardness] are listed in Tables 1 and 2.

Thus, depending on conditions, the snow density can vary from 0.03 to $0.95 \mathrm{~g} / \mathrm{cm}^{3}$.

\section{ESTIMATED ABSORPTION COEFFICIENT OF NEUTRONS IN SNOW}

The dependence of the neutron monitor count rate on the amount of snow on the roof of a building is an exponent (absorption curve):

$$
N=N_{0} e^{-h / L}
$$

Here, $N_{0}$ is the count rate of a detector (neutron monitor NM-64) with an absorber thickness $h=0$ (in this case, snow); $L$ is the neutron absorption path in snow. Relative variations in the count rate $\Delta N=\frac{N-N_{h_{0}}}{N_{h_{0}}} 100[\%]$ due to changes in snow depth are defined by the expression

$$
\Delta N=100\left[e^{-h / L}-1\right\rfloor,
$$

and the absorption path, by

$$
L=\left|h / \ln \left(\frac{\Delta N}{100}+1\right)\right|
$$

Table 3 presents the results of measurements of snow depth, its weight (per $\mathrm{cm}^{2}$ ), as well as values of $\Delta N[\%]$.

The snow depth was measured with a ruler, and the weight of snow (per $\mathrm{cm}^{2}$ ) was found from the amount of melt water from a core sample taken using a glass tube of cross-section $1 \mathrm{~cm}^{2}$. The weight of melt water was also controlled using pharmaceutical scales of the 4th accuracy class in accordance with GOST No. 14704-69 (Kofardzhiev plant, Sofia, Bulgaria, 1971 Y.O.M). The snow density found varied from 0.06 to $0.095 \mathrm{~g} / \mathrm{cm}^{3}$. In this case, the category of snow should be taken as newfallen snow (see Table 1). In winter, snow can repeatedly

Table 1

\begin{tabular}{|c|l|l|}
\hline \multicolumn{3}{|c|}{ Density of new-fallen snow } \\
\hline No. & \multicolumn{1}{|c|}{ Snow state } & $\begin{array}{c}\text { Density, } \\
\mathrm{g} / \mathrm{cm}^{3}\end{array}$ \\
\hline 1 & $\begin{array}{l}\text { Fresh fluffy dry } \\
\text { snow }\end{array}$ & $0.030-0.060$ \\
\hline 2 & Loose snow in flakes & $0.040-0.070$ \\
\hline 3 & $\begin{array}{l}\text { Loose snow in medium } \\
\text { snowflakes }\end{array}$ & $0.080-0.12$ \\
\hline 4 & $\begin{array}{l}\text { Loose snow in small } \\
\text { grains }\end{array}$ & $0.080-0.16$ \\
\hline 5 & Wet snow & $0.06-0.15$ \\
\hline 6 & Settled snow & $0.20-0.30$ \\
\hline 7 & Snow blown by the wind & $0.20-0.30$ \\
\hline
\end{tabular}


Table 2

Density of settled snow

\begin{tabular}{|c|l|l|}
\hline No. & \multicolumn{1}{|c|}{ Snow state } & \multicolumn{1}{|c|}{$\begin{array}{c}\text { Density, } \\
\mathrm{g} / \mathrm{cm}^{3}\end{array}$} \\
\hline 1 & $\begin{array}{l}\text { Snow falling during } \\
\text { several days, clean un- } \\
\text { bunched }\end{array}$ & $0.10-0.15$ \\
\hline 2 & Dry snow & 0.125 \\
\hline 3 & $\begin{array}{l}\text { Snow settled } \\
\text { to 30 days }\end{array}$ & $0.20-0.30$ \\
\hline 4 & $\begin{array}{l}\text { Snow virgin, settled } \\
\text { for more than 30 days }\end{array}$ & $0.34-0.42$ \\
\hline 5 & $\begin{array}{l}\text { Snow dry settled } \\
\text { old }\end{array}$ & $0.3-0.5$ \\
\hline 6 & $\begin{array}{l}\text { Snow wet settled } \\
\text { old }\end{array}$ & $0.6-0.8$ \\
\hline 7 & Wet snow & to 0.95 \\
\hline
\end{tabular}

fall off a rather steep roof of a building. The snow density as a function of snow depth is shown in Figure 3.

The neutron absorption path in snow was determined according to Expression (4). The average absorption path in snow was $107 \mathrm{~g} / \mathrm{cm}^{2}$. The average snow density throughout the measurement period was $0.08 \mathrm{~g} / \mathrm{cm}^{3}$. The snow density is observed to increase with snow depth. A change in snow density with depth is shown in Figure 3 by a trend line.

The linear correlation between the neutron monitor count rate and the amount of snow above the detector is depicted in Figure 4. The solid line indicates the regression line. The absorption coefficient of radiation flux recorded by the neutron monitor in snow was $\beta=-0.94$ $\% /\left(\mathrm{g} \cdot \mathrm{cm}^{-2}\right)$. This value corresponds to the absorption path of $107 \mathrm{~g} / \mathrm{cm}^{2}$.

\section{NEUTRON MONITOR DATA CORRECTION FOR PRECIPITATION IN THE FORM OF SNOW}

Neutron monitor data should be corrected for show in the same way as for atmospheric pressure variations:

$$
N_{0}(t)=N(t) \exp \left[\left(\beta_{\text {сн }} / 100\right)\left(h_{\text {снК }}(t)-h_{\text {сн } 0}\right)\right] .
$$

Here, $h_{\mathrm{SN} 0}=0$ is the absence of snow on the roof of a building; $h_{\mathrm{SNK}}(t)$ is the amount of snow on the roof at a certain moment of time $t\left[\mathrm{~g} / \mathrm{cm}^{2}\right] ; \beta_{\mathrm{SN}}$ is the absorption coefficient of neutron flux in snow $\left[\% /\left(\mathrm{g} \cdot \mathrm{cm}^{-2}\right)\right] ; N(t)$ is the neutron monitor count rate at $t$ in the presence of snow on the roof of a building; $N_{0}(t)$ is the neutron monitor count rate at $t$, reduced to $h_{\mathrm{SN} 0}=0$.

To correct the neutron monitor data for the amount of snow, the snow depth should be continuously measured on the roof of a building.

\section{CONTINUOUS MEASUREMENTS OF SNOW DEPTH}

As a snow gauge sensor we have used a phase laser rangefinder module HI50 Hi-AT Technology Co., LTD

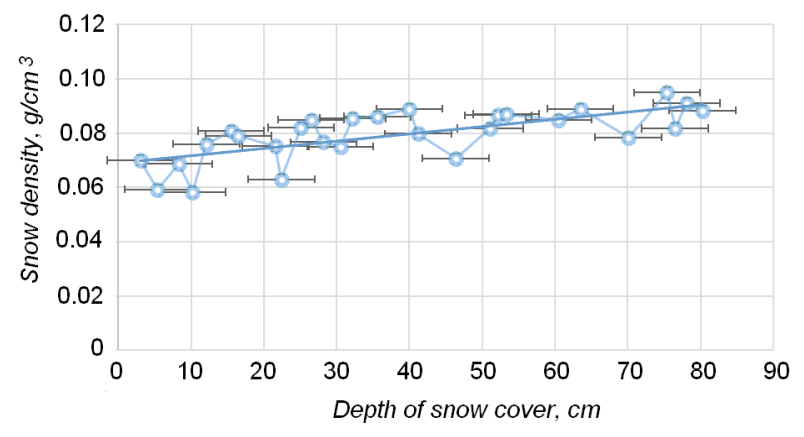

Figure 3. Snow density versus snow depth

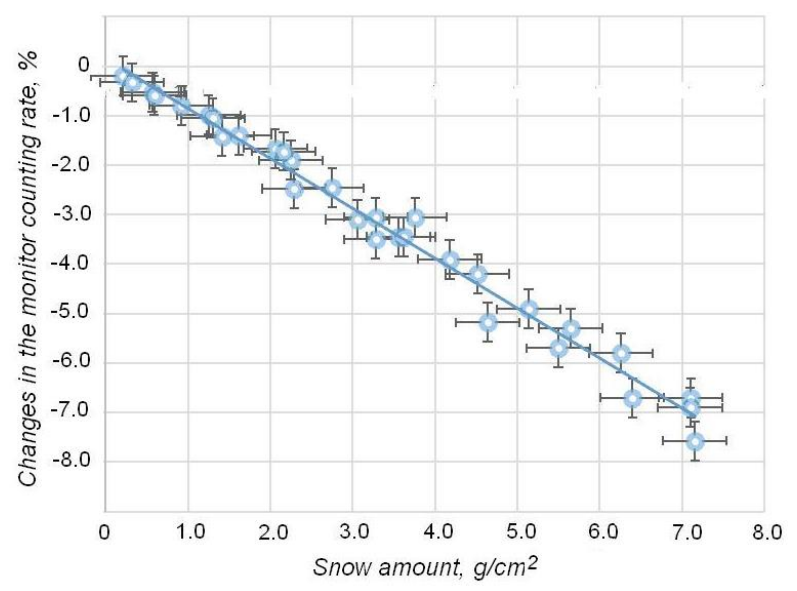

Figure 4. Count rate of the neutron monitor versus the amount of snow above it

[https://aliexpress.ru/item/32793950499.html?spm=a2g 0s.9042311.0.0.3f7d33edMI6IXU\&_ga=2.87447898. 33769789.1614593370-424972838.1577095815\&sku _id $=6396517221]$.The previously used ultrasonic rangefinder sensors had to be abandoned due to their unstable operation during strong gusts of wind $(20 \mathrm{~m} / \mathrm{s}$ or greater), snowstorms, severe snowstorms (heavy snowfalls with strong wind), as well as in calm weather with very light (fluffy) new-fallen snow.

The laser rangefinder compares favorably with ultrasonic rangefinders in its stable operation under the listed conditions: without failures during long-term testing. The general layout of the laser rangefinder module is illustrated in Figure 5.

The assembly includes an industrial control module without an LCD display (the total weight does not exceed $38 \mathrm{~g})$. The laser class is II $(635 \mathrm{~nm},<1 \mathrm{~mW})$, the measurement accuracy is $\pm 1 \mathrm{~mm}$ with a measurement duration $0.3-2.0 \mathrm{~s}$. The laser rangefinder module was placed in a case, a plastic cylinder $50 \mathrm{~mm}$ in diameter, hermetically closed (using oil seals) on both sides with plastic covers. The front cover has a window (see Figure 5) into which the module is tightly inserted. A plumbing plastic pipe is used as the case. The case with the rangefinder module was mounted on a mast above the roof of the building, where the neutron monitor is located (Figure 6).

The rangefinder is used to measure the distance $h(t)$ to the SC surface; the distance to the roof $h_{0}$ is known (const). The snow depth is found as $h_{\mathrm{SN}}(t)=h_{0}-h(t)$; and the amount of snow, as $h_{\mathrm{SNK}}(t)=\rho h_{\mathrm{SN}}(t)$, where $\rho$ is the 
Table 3

Dependence of the neutron monitor count rate on the amount of snow on the roof of a building.

\begin{tabular}{|c|c|c|c|c|c|}
\hline \multicolumn{2}{|c|}{ Amount of snow, $h$} & \multirow{2}{*}{$\begin{array}{c}\text { Snow densi- } \\
\text { ty } \rho, \\
\mathrm{g} / \mathrm{cm}^{3}\end{array}$} & \multirow{2}{*}{$\begin{array}{c}\text { Count rate } \\
\text { change } \\
\Delta N, \%\end{array}$} & \multirow{2}{*}{$\begin{array}{c}\text { Absorption } \\
\text { path } \\
L, \mathrm{~g} / \mathrm{cm}^{2}\end{array}$} & \multirow{2}{*}{$\begin{array}{c}\text { Absorption } \\
\text { coefficient } \\
\beta, \% /\left(\mathrm{g} \cdot \mathrm{cm}^{-2}\right)\end{array}$} \\
\hline $\begin{array}{c}\text { Snow } \\
\text { depth, cm }\end{array}$ & $\begin{array}{l}\text { Specific grav- } \\
\text { ity, } \mathrm{g} / \mathrm{cm}^{2}\end{array}$ & & & & \\
\hline 3.0 & 0.21 & 0.07 & -0.20 & 105.0 & -0.952 \\
\hline 5.4 & 0.32 & 0.0593 & -0.332 & 96.4 & -1.037 \\
\hline 8.3 & 0.57 & 0.0686 & -0.531 & 107.3 & -0.931 \\
\hline 10.2 & 0.59 & 0.0578 & -0.59 & 100.3 & -0.997 \\
\hline 12.1 & 0.92 & 0.076 & -0.797 & 115.4 & -0.866 \\
\hline 15.5 & 1.25 & 0.0806 & -0.996 & 126.1 & -0.793 \\
\hline 16.5 & 1.30 & 0.0788 & -1.05 & 124.5 & -0.803 \\
\hline 21.6 & 1.62 & 0.075 & -1.394 & 117 & -0.854 \\
\hline 22.4 & 1.41 & 0.0629 & -1.41 & 100.7 & -0.993 \\
\hline 25.1 & 2.06 & 0.0821 & -1.66 & 124.0 & -0.806 \\
\hline 26.5 & 2.25 & 0.0849 & -1.9 & 119.7 & -0.835 \\
\hline 28.2 & 2.16 & 0.0766 & -1.72 & 126.6 & -0.789 \\
\hline 30.5 & 2.29 & 0.0751 & -2.48 & 92.3 & -1.08 \\
\hline 32.2 & 2.75 & 0.0854 & -2.46 & 113.2 & -0.884 \\
\hline 35.6 & 3.06 & 0.0859 & -3.1 & 100.2 & -0.997 \\
\hline 40.0 & 3.56 & 0.089 & -3.45 & 104.9 & -0.953 \\
\hline 41.2 & 3.28 & 0.0796 & -3.5 & 95.3 & -1.048 \\
\hline 46.4 & 3.76 & 0.081 & -3.05 & 107.5 & -0.93 \\
\hline 51.1 & 4.18 & 0.0818 & -3.9 & 107.2 & -0.933 \\
\hline 52.2 & 4.52 & 0.0866 & -4.2 & 107.6 & -0.929 \\
\hline 53.3 & 4.64 & 0.087 & -5.18 & 91.88 & -1.08 \\
\hline 60.5 & 5.14 & 0.085 & -4.91 & 107.3 & -0.931 \\
\hline 63.5 & 5.65 & 0.089 & -5.3 & 109.4 & -0.914 \\
\hline 70.1 & 5.5 & 0.0785 & -5.7 & 96.5 & -1.036 \\
\hline 75.4 & 7.16 & 0.095 & -7.57 & 98.1 & -1.019 \\
\hline 76.5 & 6.26 & 0.0818 & -5.8 & 107.9 & -0.927 \\
\hline 78.1 & 7.11 & 0.091 & -6.7 & 109.6 & -0.912 \\
\hline 80.3 & 7.1 & 0.0884 & -6.9 & 106.4 & -0.939 \\
\hline \multicolumn{6}{|c|}{ Mean value } \\
\hline 38.6 & 3.24 & 0.08 & -3.09 & 107 & -0.94 \\
\hline
\end{tabular}

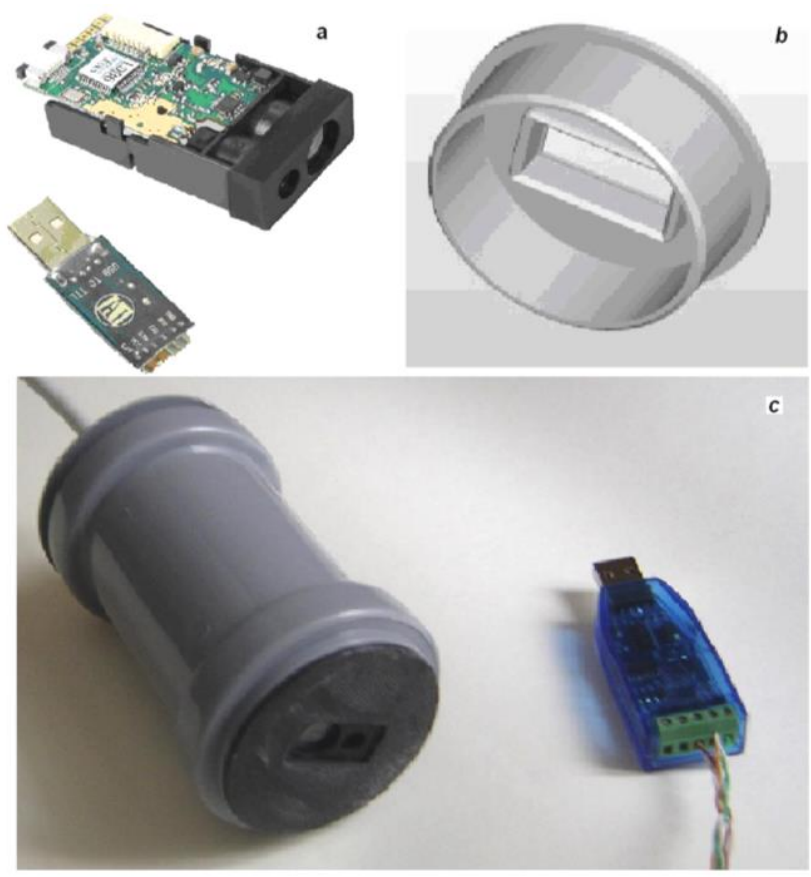

Figure 5. Laser rangefinder module (a); case cover into which the module is inserted $(b)$; rangefinder assembly $(c)$ 

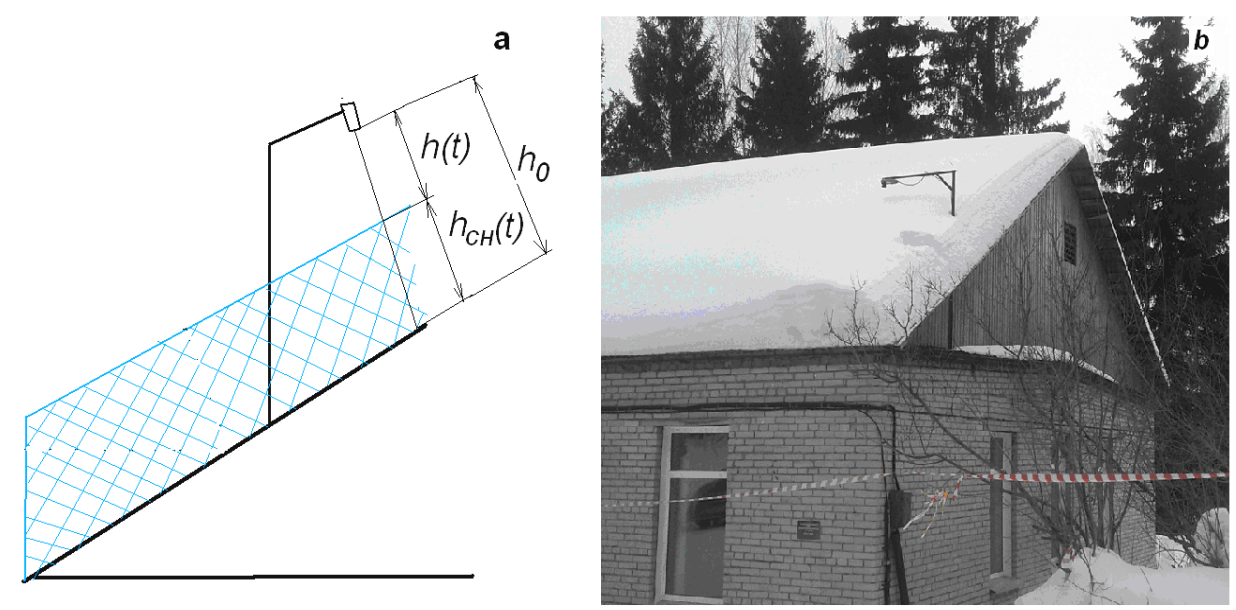

Figure 6. Installation of a snow gauge sensor above a building: scheme $(a)$ and general layout $(b)$

snow density (Figure 3). The values obtained are entered into a computer after each measurement. Figure 7 presents an example of continuous synchronous recording of the neutron monitor count rate and the snow depth above the monitor.

In the given time interval, the monitor count rate "slopes" down during gradual insignificant (less than 10 $\mathrm{cm})$ accumulation of snow. Changes in SC by $10-12 \mathrm{~cm}$ at a depth of $80 \mathrm{~cm}$ cause $0.9 \%$ variations in the monitor count rate. Figure 8 illustrates the monitor count rate at the moment of snow melting from the roof of the building.

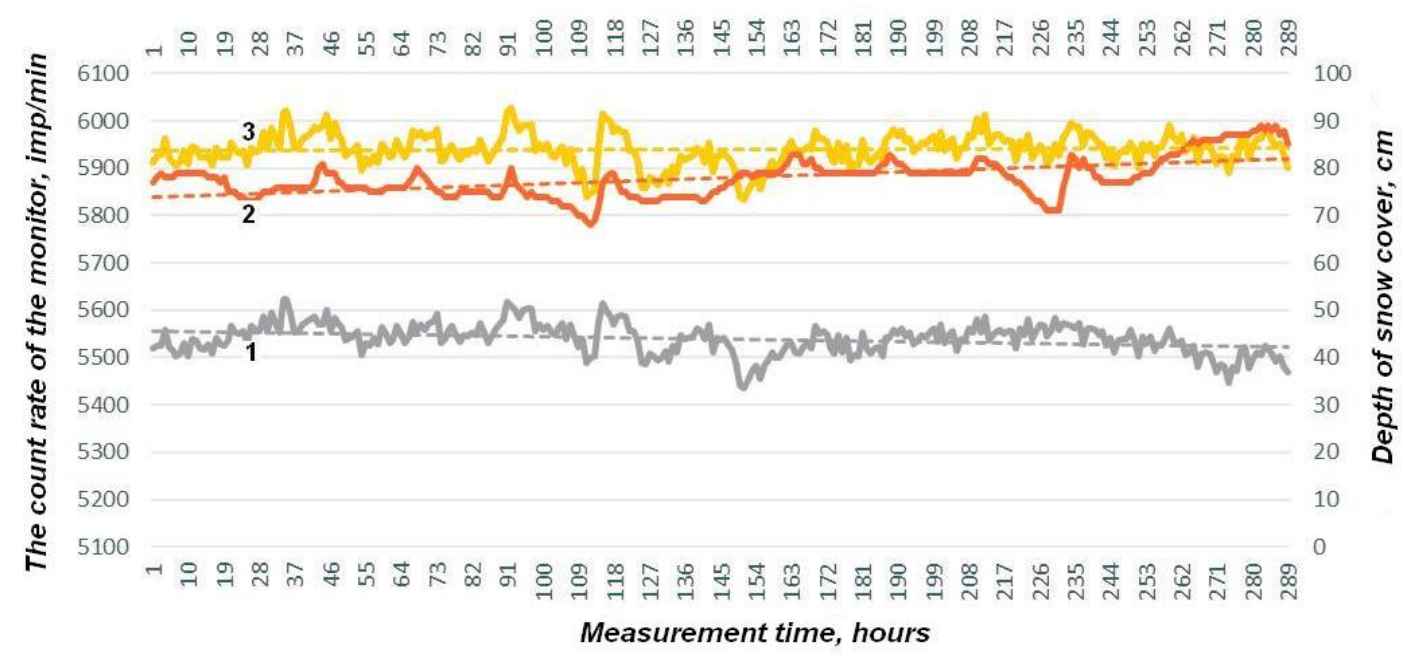

Figure 7. An example of a continuous synchronous recording of the neutron monitor count rate (curve 1) and snow depth on the roof of a building (curve 2). The monitor count rate corrected for the effect of snow is shown by curve 3. Dashed lines indicate monitor count rate trends (initial data), snow depth over the measurement period, and the monitor count rate corrected for the effect of snow.

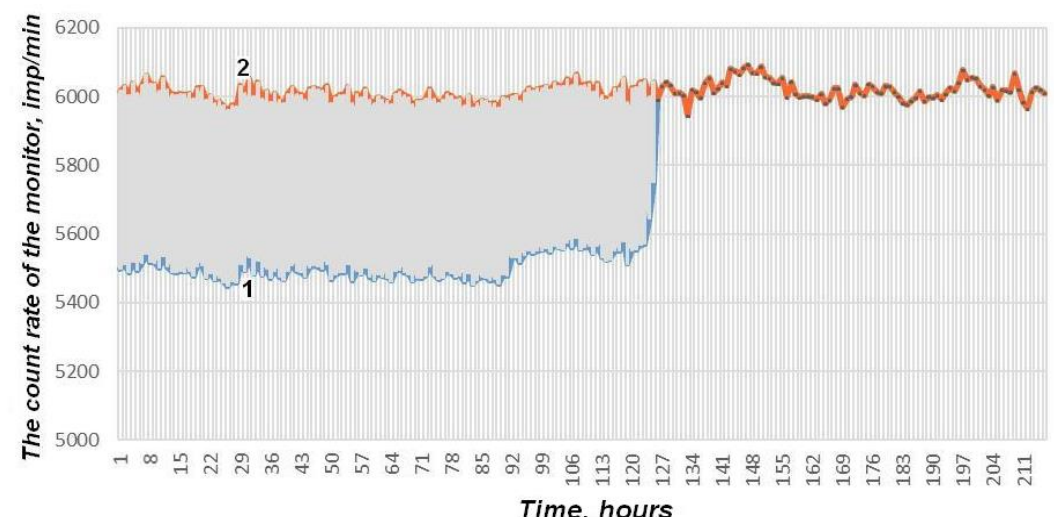

Figure 8. Change in the neutron monitor count rate when the accumulated snow melts from the roof of the building 
In Figure 8, curve 1 shows initial hourly neutron monitor data; and curve 2, data corrected for snow according to the technique presented. The total amount of snow $\sim 80 \mathrm{~cm}$ deep accumulated on the roof of the building is seen to cause the neutron monitor count rate to decrease by $\sim 8 \%$.

\section{CONCLUSION}

Accumulation of precipitation in the form of snow can lead to significant variations in the intensity of secondary cosmic rays recorded by neutron monitors. These variations, which should be attributed to meteorological effects, may be as great as several percent. To exclude the effect of precipitation from neutron monitor data, it is necessary to regularly measure the snow depth on the roof of the building in which the neutron monitor is located. The solution proposed allows us to accurately measure the snow depth and to introduce corrections to the neutron monitor data in real time.

The work is based on experimental data from the Unique Research Facility URF-85 "Russian National Network of Cosmic Ray Stations".

This work was financially supported by Basic Research program No. 0331-2019-0013 "Manifestation of processes of the deep geodynamics in geospheres as derived from monitoring of the geomagnetic field, ionosphere, and cosmic rays".

\section{REFERENCES}

Asatiani P.Ya., Blokh Ya.L., Gagua T.A. Large-size neutron counters, type SNM-15. Trudy vsesoyuznoy konferentsii po kosmicheskim lucham [Proceedings of the All-Union Conference on Cosmic Rays. Tashkent, 1968]. Moscow: Lebedev physical Institute Publ., 1969, pt. 2, iss. 3, pp. 101-104. (In Russian).

Dorman L.I. Meteorologicheskie effekty kosmicheskikh luchey [Meteorological Effects of Cosmic Rays]. Moscow, Nauka Publ., 1972, 210 p. (In Russian).

Dorman L.I. Experimentalnye i teoreticheskie osnovy astrofiziki kosmicheskikh luchey [Experimental and Theoretical Foundations of Cosmic Ray Astrophysics]. Moscow, Nauka Publ., 1975, 462 p. (In Russian).

GOST 14704-69. Laboratory balance. Weighing range and accuracy standards.
Heye B.R., Herrmann F., Jakobi J., Brogi C., Ilias A., Huisman J.A., Panagopoulos A., Pisinaras V. Monitoring of snowpack dynamics with cosmic-ray neutron probes: a comparison of four conversion methods. Front. Water. 04 August 2020. DOI: $10.3389 /$ frwa.2020.00019.

Kobelev P.G., Trefilova L.A., Belov A.V., Eroshenko E.A., Yanke V.G. Reference station method for eliminating snow effect based on data for 2018-2019. Fizika avroral'nykh yavleniy. Trudy XLII ezhegodnogo semenara. [Physics of Auroral Phenomena. Proc. XLII Annual Seminar]. Apatity, 2020, pp. 52-55. (In Russian).

Rivera Villarreyes C.A., Baroni G., Oswald S.E. Integral quantification of seasonal soil moisture changes in farmland by cosmic ray neutrons. Hydrology and Earth System Science. 2011, vol. 15, iss. 12 , pp. 3843-3859. DOI: $10.5194 /$ hess-153843-2011.

Schattan P., Baroni G., Oswald S.E., Schöber J., Fey C., Kormann C., Huttenlau M., Achleitner S. Continuous monitoring of snowpack dynamics in alpine terrain by aboveground neutron sensing. Water Resources Research. 2017, vol. 53, iss. 5, pp. 3615-3634. DOI: 10.1002/2016WR020234.

Sigouin M.J.P., Si B.C. Calibration of a non-invasive cosmic-ray probe for wide area snow water equivalent measurement. The Cryosphere. 2016, vol. 10, pp. 1181-1190. DOI: 10.5194/tc-10-1181-2016.

Yanchukovsky V.L., Filimonov G.Ya. Coupling coefficients and atmospheric multiplicity of the neutron component of secondary cosmic rays. Izvestiya RAN. Seriya fizicheskaya [Bulletin of the Russian Academy of Sciences. Physics]. 1995, no 4, pp. 125-128. (In Russian).

URL: https://tehtab.ru/Guide/GuideMedias/GuideWater/SnowDensit yAndHardness (accessed April 2, 2021).

URL: https://aliexpress.ru/item/32793950499.html?spm= a2g0s.9042311.0.0.3f7d33edMI6IXU\&_ga=2.87447898.3376 9789.1614593370-

424972838.1577095815\&sku_id=6396517221 (accessed April 2, 2021).

How to cite this article

Yanchukovsky V.L., Kuzmenko V.S. Method of automatic correction of neutron monitor data for precipitation in the form of snow in real time. Solar-Terrestrial Physics. 2021. Vol. 7. Iss. 3. P. 114-120. DOI: $10.12737 /$ stp-73202108. 